\title{
CARACTERIZAÇÃO MOLECULAR DOS \\ ALELOS-S DE INCOMPATIBILIDADE GAMETOFÍTICA \\ EM Prunus salicina Lindl. ${ }^{1}$

\author{
MONALIZE SALETE MOTA², VALMOR JOÃO BIANCHI ${ }^{3}$, \\ JOSÉ ANTÔNIO PETERS ${ }^{3}$
} ALEXANDRE ZANARDO DE CARVALHO ${ }^{4}$, EUGENIA JACIRA BOLACEL BRAGA 5 ,
}

RESUMO-Pomares comerciais de ameixeira-japonesa devem conter pelo menos duas cultivares para obter boa fertilização, devido à presença do sistema de incompatibilidade gametofítica, que inibe a autofecundação da grande maioria das cultivares. No presente trabalho, buscou-se identificar e caracterizar molecularmente os alelos-S de 11 cultivares de ameixeira-japonesa (Prunus salicina Lindl.) e verificar a compatibilidade entre os genótipos avaliados. As cultivares Santa Rosa, Santa Rita, Reubennel, Pluma 7, América, Rosa Mineira, Amarelinha, The First, Gulfblaze (Clone São Paulo), Gulfblaze (Clone Guaiba) e Harry Pickstone foram analisadas por meio de Reação em Cadeia da Polimerase (PCR) com três pares de iniciadores específicos para alelos-S. As condições da PCR utilizadas, bem como as combinações de iniciadores, permitiram a identificação de alelos- $S$ nas cultivares de $P$. salicina estudadas, bem como a indicação dos polinizadores mais compatíveis com algumas das principais cultivares utilizadas na produção de frutas. O sequenciamento de alguns dos alelos-S amplificados revelou elevada similaridade com sequências de nucleotídeos já identificados em outros trabalhos com Prunus spp.. Entretanto, a obtenção de sequências completas de maior número de alelos-S faz-se necessária para o estabelecimento de uma relação de identidade precisa entre os mesmos.

Termos para Indexação: Ameixeira-japonesa, autoincompatibilidade gametofítica, PCR, alelos-S.

\section{MOLECULAR IDENTIFICATION OF S-ALLELES OF GAMETOPHYTIC INCOMPATIBILITY IN Prunus salicina Lindl.}

\begin{abstract}
Commercial plum orchards must contain at least two cultivars, in order to ensure good fruit set and thus high economic yields, because its carries the gametophytic incompatibility system, that inhibits the self-pollination in a great number of cultivars. The aim of this work was to identify by PCR (Polymerase Chain Reaction) the S-alleles related to gametophytic incompatibility in eleven Prunus salicina (Lindl.) cultivars. The Santa Rosa, Santa Rita, Reubennel, Pluma 7, America, Rosa Mineira, Amarelinha, The First, Gulfblaze (Clone São Paulo), Gulfblaze (Clone Guaíba) e Harry Pickstone cultivars were analysed using three pairs of specific primers for amplifying the S-alleles. The PCR conditions and primers set allowed a characterization of S-alleles in the japonese plum and the identification of the most compatible pollinators to some commercial cultivars. Sequencing analysis of some amplified S-alleles showed high similarity to nucleotides sequences already identified in other studies with Prunus spp.. However, complete sequences of a large number of S-alleles it is necessary to get a more precisely identity of relationship among this S-alleles. Index terms: Japanese plum, gametophytic self-incompatibility, PCR, S-alleles.
\end{abstract}

\footnotetext{
1(Trabalho 166-09). Recebido em: 08-07-2009. Aceito para Publicação em: 03-03-2010.

${ }^{2}$ Mestre em Fisiologia Vegetal, PPGFV - Departamento de Botânica - Instituto de Biologia - Universidade Federal de Pelotas - RS, email: monalizem@yahoo.com.br.

${ }^{3}$ Eng. Agron., Prof. Dr. do Departamento de Botânica - Instituto de Biologia - Universidade Federal de Pelotas - RS, email: valmorjb@yahoo.com; japeters1@hotmail.com

${ }^{4}$ Biólogo, Mestre em Biotecnologia, Universidade Federal de Pelotas - RS, email : alezc@bol.com.br

${ }^{5}$ Bióloga, Prof. Dra. do Departamento de Botânica - Instituto de Biologia - Universidade Federal de Pelotas - RS, email : jacirabraga@hotmail.com
} 


\section{INTRODUÇÃO}

Embora a produção brasileira de ameixa tenha crescido nos últimos anos, a área cultivada tem grande potencial para ampliação, pois o volume produzido da fruta ainda é insuficiente para atender à demanda interna. De acordo com Chagas et al. (2007), anualmente, o Brasil importa cerca de 20 mil toneladas de ameixas, o que representa um terço do que é consumido. Dentre as espécies cultivadas no Brasil, predomina a Prunus salicina Lindl, conhecida como ameixeira-japonesa que, de acordo com Seganfredo (1995), encontra condições favoráveis para seu cultivo, principalmente nos Estados do Rio Grande do Sul, Santa Catarina, Paraná e São Paulo.

Mesmo com grande potencial de cultivo, alguns fatores têm limitado o aumento da produção nacional de ameixas, sendo o principal a escaldadura das folhas, uma doença causada pela bactéria Xylella fastidiosa, registrada na Argentina desde 1935 e detectada a sua disseminação no Sul do Brasil, a partir de 1975 (SILVEIRA et al., 2003), bem como a variabilidade de clima, o uso de porta-enxertos inadequados e a incapacidade de autopolinização de muitas cultivares (RASEIRA, 2003). A maioria das cultivares de $P$. salicina são autoinférteis, devido ao sistema de autoincompatibilidade gametofítica, determinado pela presença de um loco multialélico, contendo os denominados alelos- $S$, que codificam para enzimas que interrompem a formação do tubo polínico no processo de polinização (KAUFMANN et al., 1992; NEWBIGIN et al., 1993; BOSKOVIC; TOBUTT, 1996; DE NETTANCOURT, 1997, 2000; SAPIR et al., 2004). Como resultado, existe a necessidade do uso de outras cultivares de ameixeira, que servirão como polinizadoras das cultivares produtoras, possibilitando a fecundação, frutificação e boa produção de frutos.

A autoincompatibilidade gametofítica é o sistema mais comum entre as plantas e supõe-se ser o mais primitivo. Esse sistema apresenta três tipos de interação de compatibilidade: totalmente incompatível, quando ambos os alelos são comuns; parcialmente compatível em que apenas um alelo é diferente; e totalmente compatível, quando os quatro alelos são diferentes e a fecundação ocorre plenamente (KAUFMANN et al., 1992; NEWBIGIN et al., 1993; LEWIS, 1994; SAKURAI, 2000; BRUCKNER,1994),

Métodos que permitam avaliar antecipadamente a compatibilidade genética de alelos-S entre cultivares são de grande interesse, na medida em que permitem selecionar precocemente cultivares totalmente compatíveis, do ponto de vista genéticoreprodutivo (MOTA;OLIVEIRA, 2005). Muito embora não permita substituir por completo os ensaios de polinização controlada a campo, a avaliação molecular dos alelos- $S$ torna o processo de seleção de uma polinizadora mais eficiente (BROOTHAERTS et al., 1995; ISHIMIZU et al., 1999; YAEGAKI et al., 2001).

A identificação e caracterização dos alelos-S, bem como o entendimento a respeito da autoincompatibilidade reprodutiva de cada cultivar, torna-se de extrema importância nos estudos de melhoramento genético e no manejo de pomares de ameixeirajaponesa, na tentativa de melhorar a frutificação efetiva e sua produtividade.

O objetivo da realização deste trabalho foi identificar e caracterizar molecularmente os alelos-S relacionados à incompatibilidade gametofítica, em 11 cultivares de $P$. salicina, visando a auxiliar produtores e melhoristas na escolha dos melhores genótipos para polinização cruzada em programas de melhoramento e no manejo reprodutivo de pomares comerciais.

\section{MATERIAL E MÉTODOS}

O material vegetal utilizado para a realização das análises constituiu-se de folhas jovens, completamente expandidas, retiradas das cultivares de ameixeira-japonesa (P. salicina Lindl.) Santa Rosa, Santa Rita, Reubennel, Pluma 7, América, Rosa Mineira, Amarelinha, The First, Harry Pickstone, Gulfblaze (Clone São Paulo ou CSP) e Gulfblaze (Clone Guaíba ou CG), coletadas no viveiro da Frutiplan-Pelotas-RS e na Embrapa Clima Temperado-Pelotas-RS. O DNA foi extraído usando o método descrito por Doyle e Doyle (1991), a partir de $75 \mathrm{mg}$ de folhas e, após a quantificação do DNA, foram feitas diluições para uma concentração final de $5 \mathrm{ng}_{\mu \mathrm{l}^{-1}}$.

Para as reações de PCR, foram utilizados 20 ng de DNA de cada amostra; $2,5 \mu 1$ de 10x PCR buffer; $1.500 \mu \mathrm{M}$ de $\mathrm{MgCl}_{2 .} 0,4 \mu \mathrm{M}$ de cada iniciador (Tab. 1); $150 \mu \mathrm{M}$ de cada dNTPs; $1,25 \mathrm{U}$ de Taq DNA polimerase (Invitrogen) e água Milli-Q para um volume final de $25 \mu$ l. Os iniciadores utilizados foram as combinações Pru- $\mathrm{C}_{2} / \mathrm{PCE}-\mathrm{R}$ (YAMANE et al., 2001; TAO et al., 1999), Pru-C 2 /Pru-C 5 (TAO et al., 1999) e $\mathrm{IZ}_{1} / \mathrm{IZ}_{4}$ (SAPIR, 2004).

A amplificação do DNA foi realizada em termociclador (PCR Sprint - Thermo Electron Corporation) com o perfil térmico inicial de $94^{\circ} \mathrm{C}$ por 5 min, $54^{\circ} \mathrm{C}$ por $2 \mathrm{~min}$, e $72^{\circ} \mathrm{C}$ por 3 min seguido de 35 ciclos de $94^{\circ} \mathrm{C}$ por $1 \mathrm{~min}, 54^{\circ} \mathrm{C}$ por $2 \min 72^{\circ} \mathrm{C}$ por $3 \mathrm{~min}$. e com um ciclo final de $94^{\circ} \mathrm{C}$ por $1 \mathrm{~min}$, $54^{\circ} \mathrm{C}$ por $2 \mathrm{~min}, 72^{\circ} \mathrm{C}$ por $10 \mathrm{~min}$. Os fragmentos de 
DNA amplificados foram submetidos à eletroforese em gel de agarose a $2 \%$, a $5 \mathrm{~V} \mathrm{~cm}^{-1}$, usando como padrão o marcador de massa molecular o DNA Ladder $100 \mathrm{pb}$ (Invitrogen).

Oito produtos da PCR foram submetidos ao sequenciamento para verificar a identidade dos alelos. Amostras de $100 \mathrm{ng}$ de DNA amplificado, correspondentes a alelos-S isolados e purificados dos géis de agarose, foram sequenciados, utilizando o kit DYEnamic ${ }^{\mathrm{TM}}$ ET termination (Amershal Biosciences), conforme protocolo do fabricante. Utilizou-se um sequenciador automático MegaBACE 500 (Amershal Biosciences), e os fragmentos amplificados foram sequenciados três vezes para confirmação dos resultados.

A qualidade das sequências de nucleotídeos foi analisada pela sobreposição dos fragmentos, utilizando o software Vector NTI Advance 10.0, AlignX e Contig Express (InforMax, Inc.). A determinação da sequência consenso foi feita pelo alinhamento dos produtos obtidos, utilizando o software ClustalX (THOMPSON et al., 1997). A natureza das sequências foi confirmada por meio de alinhamento e comparação com sequências depositadas no banco de dados de nucleotídeos no BLAST do NCBI (National Center for Biotechnology Infomation - http://www. ncbi.nlm.nih.gov/BLAST).

\section{RESULTADOS E DISCUSSÃO}

\section{Amplificação de alelos-S}

A combinação de iniciadores Pru- $\mathrm{C}_{2} / \mathrm{PCE}-\mathrm{R}$ permitiu a amplificação de dois alelos distintos em cada uma das 11 cultivares avaliadas (Fig. 1), com exceção de 'Pluma 7', 'The First', 'Gulfblaze - CSP' e 'Gulfblaze - CG', que apresentaram apenas um alelo amplificado. A combinação dos iniciadores, Pru- $\mathrm{C}_{2} /$ Pru- $\mathrm{C}_{5}$ (Fig. 1) amplificou alelos-S em 10 cultivares (91\%), destas, oito cultivares com duas alelos e em duas apenas um único alelo foi amplificado ("The First' e 'Gulfblaze - CG'). A cultivar 'Gulfblaze CSP' não teve alelos amplificados com esses iniciadores, apesar das inúmeras repetições de PCR, podendo ser um indicativo de que essa cultivar possui alelos nulos para esse loco, justificado pelo fato de que os iniciadores não foram desenvolvidos para cultivares de ameixeira. A combinação dos iniciadores $\mathrm{IZ}_{1} /$ $\mathrm{IZ}_{4}$ (Fig. 2) permitiu a amplificação de alelos em apenas três cultivares $(27,3 \%)$ e, em cada uma delas, apresentou um único alelo, possivelmente devido ao fato de os iniciadores terem sido desenvolvidos para alelos-S específicos, conforme relatado por Sapir et al. (2004) em suas pesquisas com cultivares de ameixeira-japonesa.
Seis diferentes alelos foram obtidos, entre as 11 cultivares avaliadas, com cada uma das combinações de iniciadores Pru- $\mathrm{C}_{2} /$ Pru- $\mathrm{C}_{5}$ e Pru- $\mathrm{C}_{2} / \mathrm{PCE}-\mathrm{R}$, sendo amplificados alelos de tamanho variando entre 1.900 e $600 \mathrm{pb}$ e 1.400 e $400 \mathrm{pb}$, respectivamente. A combinação de iniciadores $\mathrm{IZ}_{1} / \mathrm{IZ}_{4}$ amplificou um único alelo, com aproximadamente $460 \mathrm{pb}$ (Tab. 2), nas cvs. Santa Rosa, América e Gulfblaze (CG).

Quando comparados os produtos da PCR dos diferentes conjuntos de iniciadores, Pru- $\mathrm{C}_{2} /$ Pru- $\mathrm{C}_{5}$ com Pru- $\mathrm{C}_{2} /$ PCE-R, observou-se que a reação de amplificação produziu fragmentos com tamanhos diferentes, devido a diferenças no número de nucleotídeos da sequência hipervariável interna aos pontos de ligação desses iniciadores em cada cultivar (Fig. 3), porém observando o padrão de amplificação em cada gel, verifica-se um padrão similar de distribuição das bandas em cada cultivar analisada com os dois conjuntos de iniciadores, sendo que os alelos amplificados com os iniciadores Pru- $\mathrm{C}_{2} / \mathrm{PCE}-\mathrm{R}$ são proporcionalmente menores em relação aos amplificados com Pru- $\mathrm{C}_{2} /$ Pru- $\mathrm{C}_{5}$, explicado pelo fato de o iniciador PCE-R possuir sítio de anelamento mais próximo à Pru- $\mathrm{C}_{2}$ em relação à $\mathrm{Pru}-\mathrm{C}_{5}$ (Fig. 3). Variações de produtos amplificados entre os conjuntos de iniciadores Pru- $\mathrm{C}_{2} /$ Pru- $\mathrm{C}_{5}$ e Pru- $\mathrm{T}_{2} / \mathrm{PCE}$ foram observadas nas pesquisas realizadas por Beppu et al. (2002). De acordo com esses autores, os alelos de mesmo padrão de banda são derivados da mesma sequência do gene que codifica para S-RNAse em P. salicina.

Embora o padrão de amplificação tenha sido semelhante entre os conjuntos de iniciadores acima citados, a cultivar 'Pluma 7' apresentou dois alelos com os iniciadores Pru- $\mathrm{C}_{2} /$ Pru- $\mathrm{C}_{5}$ e apenas um alelo com Pru-C, $/$ PCE-R. Já a cultivar 'Gulfblaze -CSP' não teve alelos-S amplificados com Pru- $\mathrm{C}_{2} /$ Pru- $\mathrm{C}_{5}$ e apenas um alelo amplificado com Pru- $\mathrm{C}_{2} / \mathrm{PCE}-\mathrm{R}$.

Pesquisas realizadas em genótipos de cerejeira, amendoeira e damasqueiro, usando os iniciadores Pru-C2/Pru-C5 (TAO et al. 1999) e os iniciadores Pru-C2/PCE-R, nas mesmas espécies (YAMANE et al. 2001), também foram observadas variações no número de alelos entre locos e ausência de amplificação em algumas cultivares. Esse resultado, em alguns casos, é justificado pela ocorrência de apenas um alelo ou de alelos nulos para aquele loco gênico. Alelos nulos são descritos em diversos sistemas de microssatélites e são resultantes de mutações, tais como substituição, inserções e deleções em uma ou em ambas as regiões de anelamento dos iniciadores a sequência homóloga do DNA molde (CALLEN et al., 1993). 


\section{Compatibilidade entre cultivares e suas polinizadoras}

De acordo com Barbosa (2006), a característica fundamental de uma planta polinizadora é que seu florescimento seja sincrônico com a cultivar produtora e, essencialmente, deverá ser compatível com a mesma, ou seja, seu pólen deverá efetivamente fecundar o pistilo da cultivar produtora, caso contrário não haverá produção. Entretanto, o período de floração das cultivares polinizadoras pode ser influenciado por condições climáticas, como chuva, vento, geadas, seca, entre outros, e assim ocasionar variação na polinização efetiva.

A cultivar 'Santa Rosa', (Figura 1 e Tabela 2), apresentou alelos de mesmo tamanho que as cultivares 'América' e 'Harry Pisckstone' quando usados os iniciadores Pru- $\mathrm{C}_{2} /$ Pru- $\mathrm{C}_{5}$, e quando usados os iniciadores Pru- $\mathrm{C}_{2} / \mathrm{PCE}-\mathrm{R}$, 'Santa Rosa' e 'Harry Pisckstone' também tiveram alelos com o mesmo número de pares de base. Essas evidências sugerem que as três cultivares apresentam autoincompatibilidade e, dentre as 11 cultivares testadas, são as únicas com incompatibilidade total entre si.

Baseado nos resultados obtidos neste trabalho, a relação de autoincompatibilidade de alelos-S entre as cultivares pôde ser inferida. Verificou-se semicompatibilidade ( $\mathrm{SC}$ ) entre cultivares que tiveram amplificados dois alelos, porém apenas um deles idêntico (Tabela 2). Outras cultivares apresentaram todos os alelos diferentes entre si, sendo considerados totalmente compatíveis (C). Cultivares que amplificaram apenas um alelo, podem ser consideradas como autoincompatíveis parciais (AIP), como é o caso de 'The First' e 'Gulfblaze -CG' verificado pela amplificação com os iniciadores Pru- $\mathrm{C}_{2} /$ Pru- $\mathrm{C}_{5}$ e também com Pru-C $\mathrm{C}_{2}$ e PCE-R. Com este último par de iniciadores, a cultivar 'Pluma 7' mostrou-se autoincompatível parcial, enquanto com os iniciadores Pru- $\mathrm{C}_{2} /$ Pru- $\mathrm{C}_{5}$ foi autoincompatível, amplificando dois alelos.

A compatibilidade entre muitas cultivares de ameixeira-japonesa vem sendo determinada através de métodos convencionais de polinização e testes de crescimento do tubo polínico (Tabela 3). A partir da identificação molecular dos alelos- $S$, é possível propor nova relação de polinizadores para as cultivares estudadas (Tabela 3), principalmente para uso em hibridações controladas no processo de melhoramento, porém não dispensando a validação associada com estudos a campo. A cultivar 'Rosa Mineira', que é conhecida por apresentar relativa autofertilidade, mostrou-se compatível com um número maior de cultivares do que as demais, confirmando o que os estudos e as práticas de seleção convencional já haviam estabelecido.

Baseando-se nestes dados de compatibilidade molecular, a escolha dos melhores polinizadores deverá ser feita levando em consideração, ainda, a variabilidade das condições de clima, principalmente de temperatura e da época de floração. É recomendado o uso de mais de um polinizador por cultivar comercial, uma vez que, sob determinadas condições climáticas, a floração poderá não coincidir completamente (EMBRAPA, 2005). Sendo assim, os dados da Tabela 3, relativos à recomendação baseada em dados moleculares, são válidos para uso em trabalhos de melhoramento genético, onde as hibridações são controladas e utilizam pólen colhido em anos anteriores, para aquelas cultivares de floração precoce, ou então para aquelas que apresentam coincidência total ou parcial na época de floração, para uma determinada região de produção.

Beppu et al. (2002) analisaram diversas cultivares de ameixeira-japonesa com os iniciadores Pru$\mathrm{C}_{2}$ /PCE-R, dentre elas 'Santa Rosa', Late Santa Rosa' e 'Beauty', consideradas autocompatíveis. A cultivar 'Santa Rosa' apresentou alelos de tamanho em torno de 1.170 e $1.420 \mathrm{pb}$, os quais foram denominados de $\mathrm{S}^{\mathrm{c}}$ e $\mathrm{S}^{\mathrm{e}}$, respectivamente. Também 'Oishiwasesumomo' e 'Tayo' apresentaram o alelo $\mathrm{S}^{\mathrm{c}}$ e mostraram-se autoincompatíveis. Enquanto a cultivar 'Rio', que possui o alelo $\mathrm{S}^{\mathrm{e}}$, apresentou crescimento do tubo polínico normal, ou seja, mostrou-se autocompatível, o que demonstra que o alelo $S^{\mathrm{e}}$ pode estar envolvido na supressão da autoincompatibilidade em cultivares que apresentam este alelo. Tao et al. (2002a e b) também encontraram em cultivares de damasqueiro-japonês um gene para S-RNase que poderia ser utilizado como marcador molecular de autocompatibilidade, assim como o alelo $\mathrm{S}^{\mathrm{e}}$.

Esses resultados permitem inferir que a identificação de alelos-S com efeito sobre a supressão da autoincompatibilidade, em ameixeira-japonesa, poderá ser potencial marcadora molecular para a seleção de novos genótipos autoférteis e/ou parcialmente autoférteis.

\section{plificados}

Análise de Sequenciamento de alelos am-

Das cultivares 'América', 'Rosa Mineira', 'Santa Rita' e 'Santa Rosa', foi possível isolar alguns alelos amplificados e obter DNA suficiente para o sequenciamento (Tab. 4). As sequências parciais foram comparadas com as de alelos-S de P. salicina depositadas no GenBank, revelando que o produto da amplificação com os iniciadores $\mathrm{IZ}_{1} / \mathrm{IZ}_{4}$, da cultivar 'América' apresentou $100 \%$ de identidade com o alelo Sc (SAPIR;GOLDWAY - BLAST 2006) e 99\% de identidade com o alelo $\mathrm{S}^{4}$ (SAPIR;GOLDWAY, 
2001-BLAST). A mesma percentagem de identidade foi apresentada pela cultivar 'Santa Rosa' para ambos os alelos, $\mathrm{S}^{\mathrm{c}}$ e $\mathrm{S}^{4}$, conforme Sapir e Goldway (2006)-BLAST, indicando tratar-se do mesmo alelo, visto que, na visualização dos produtos amplificados (Fig. 2), constatou-se serem alelos de tamanhos semelhantes. Mesmo assim, pequenas diferenças no tamanho dos fragmentos podem ocorrer em função da perda de algumas bases durante o processo de isolamento e purificação do produto de PCR ou mesmo da perda das extremidades durante o sequenciamento.

De acordo com Schifino-Wittmann e Dall'Agnol (2002), existem algumas espécies consideradas autoincompatíveis, mas na prática apresentam certa fertilidade. Isso aconteceria em função da ativação de genes que têm como função restaurar a fertilidade, de modo a permitir que ocorram o crescimento do tubo polínico e a consequente fecundação, como no caso do alelo $\mathrm{S}^{\mathrm{f}}$ em damasqueiro, que ocorre naturalmente ou surgem como resultado de mutações ou poliploidização.

$\mathrm{Na}$ amplificação com os iniciadores $\mathrm{Pru}-\mathrm{C}_{2} /$ Pru-C ${ }_{5}$, o alelo de 'Santa Rita' apresentou 94\% de identidade com o alelo $\mathrm{S}^{\mathrm{h}}$ (BEPPU et al., 2002), enquanto o alelo de 'América' não apresentou identidade com nenhuma sequência que codifica para S-RNases, possivelmente devido ao fato de a sequência isolada ter sido consideravelmente pequena e insuficiente para uma análise adequada.

Os alelos amplificados a partir da cultivar 'Rosa Mineira', para os locos Pru- $\mathrm{C}_{2} /$ Pru- $_{5}$ (600 pb e $800 \mathrm{pb}$ ), foram sequenciados individualmente com os iniciadores Pru- $\mathrm{C}_{2}$ e Pru- $\mathrm{C}_{5}$, revelando $87 \%$ e $94 \%$ de identidade, respectivamente, com o alelo $\mathrm{S}^{\mathrm{i}}(410 \mathrm{pb})$ identificado em ameixeira (BEPPU et al., 2002-BLAST) e $88 \%$ de identidade com o alelo $\mathrm{S}^{\text {a }}$ (470pb) (TAO et al., 2006-BLAST), Tab. 4. Para o loco Pru-C $/ 2$ PCE-R, o alelo de 500pb apresentou $90 \%$ de identidade com o alelo $\mathrm{S}^{\mathrm{h}}$ (520pb) (ZHANG et al., 2006; BEPPU et al., 2002-BLAST), enquanto o fragmento de $400 \mathrm{pb}$ revelou $82 \%$ de identidade com $\mathrm{S}^{\mathrm{a}}$ (TAO et al., 2006-BLAST), (Tab. 4). De acordo com esses resultados, verificou-se que os alelos amplificados com os iniciadores Pru- $\mathrm{C}_{2} / \mathrm{PCE}-\mathrm{R}$ (400pb e 500pb) em 'Rosa Mineira' são similares aos alelos $\mathrm{S}^{\mathrm{i}}$ e $\mathrm{S}^{\mathrm{h}}$, respectivamente, encontrados no estudo de Beppu et al. (2002).

De maneira similar, Sapir et al. (2004) testaram diversas combinações de iniciadores nas cultivares 'Wickson', 'Royal Zee' e a polinizadora 'Red Beaut' e obtiveram a amplificação dos alelos $S^{1}, S^{3}$, $\mathrm{S}^{4}, \mathrm{~S}^{5}$ e $\mathrm{S}^{6}$, para o loco Pru- $\mathrm{C}_{2} /$ Pru- $\mathrm{C}_{4} \mathrm{R}$. A análise da sequência do alelo $\mathrm{S}^{1}$ revelou tratar-se do mesmo alelo $\mathrm{S}^{\mathrm{a}}$, isolado e analisado por Yamane et al. (1999).
Para a cultivar 'Santa Rosa', na amplificação com os iniciadores Pru- $\mathrm{C}_{2} / \mathrm{PCE}-\mathrm{R}$, obtiveram-se alelos com tamanho aproximado de $1.400 \mathrm{pb}$ e 1.200 $\mathrm{pb}$, que apresentam similaridade em tamanho com os alelos $\mathrm{S}^{\mathrm{e}}$ e $\mathrm{S}^{\mathrm{c}}$ identificados no trabalho de Beppu et al. (2002). Os resultados obtidos levam a sugerir que o alelo $\mathrm{S}^{\mathrm{e}}(1.400 \mathrm{pb})$ poderá estar associado à autocompatibilidade, pois estando presente na cultivar 'Santa Rosa' pode ser o responsável pela relativa autofertilidade observada nas condições de cultivo da região Sul do Brasil, em pomares implantados sem polinizadores ou mesmo na ausência de coincidência de floração com o polinizador. Por outro lado, as cultivares 'Reubennel', Pluma 7', 'América', 'Amarelina' e 'Harry Pickstone' compartilham o mesmo alelo de $1.400 \mathrm{pb}$, porém não apresentam o mesmo comportamento reprodutivo de 'Santa Rosa'. Em testes de polinização controlada, realizados com a cultivar 'América', verificou-se que este é completamente autoincompatível (dados não divulgados).

Em cultivares onde é relatada compatibilidade gametofítica parcial, a identificação desse tipo de evento, normalmente, é baseada na avaliação da frutificação efetiva. Sendo assim, é necessária a condução de novos estudos a fim de determinar a exata sequência do alelo $\mathrm{S}^{\mathrm{e}}(1.400 \mathrm{pb})$ em 'Santa Rosa' e outras cultivares que compartilham o mesmo alelo, buscando comprovar seu envolvimento na autofertilidade, além da realização de testes de polinização controlada.

A análise de alelos-S baseado na PCR é um método com grande potencial de aplicação para identificar grupos de cultivares autoincompatíveis. $\mathrm{O}$ conhecimento dos alelos-S, responsáveis pela incompatibilidade gametofítica, bem como a identificação de um alelo-S que possa suprimir essa incompatibilidade, possibilitará a transferência controlada desses alelos entre cultivares que apresentem sincronia de floração e, com isso, aumentar a eficiência dos programas de melhoramento genético na obtenção de novas cultivares, facilitando o manejo reprodutivo dos pomares, visando a melhorar a fecundação e o fruit set. 


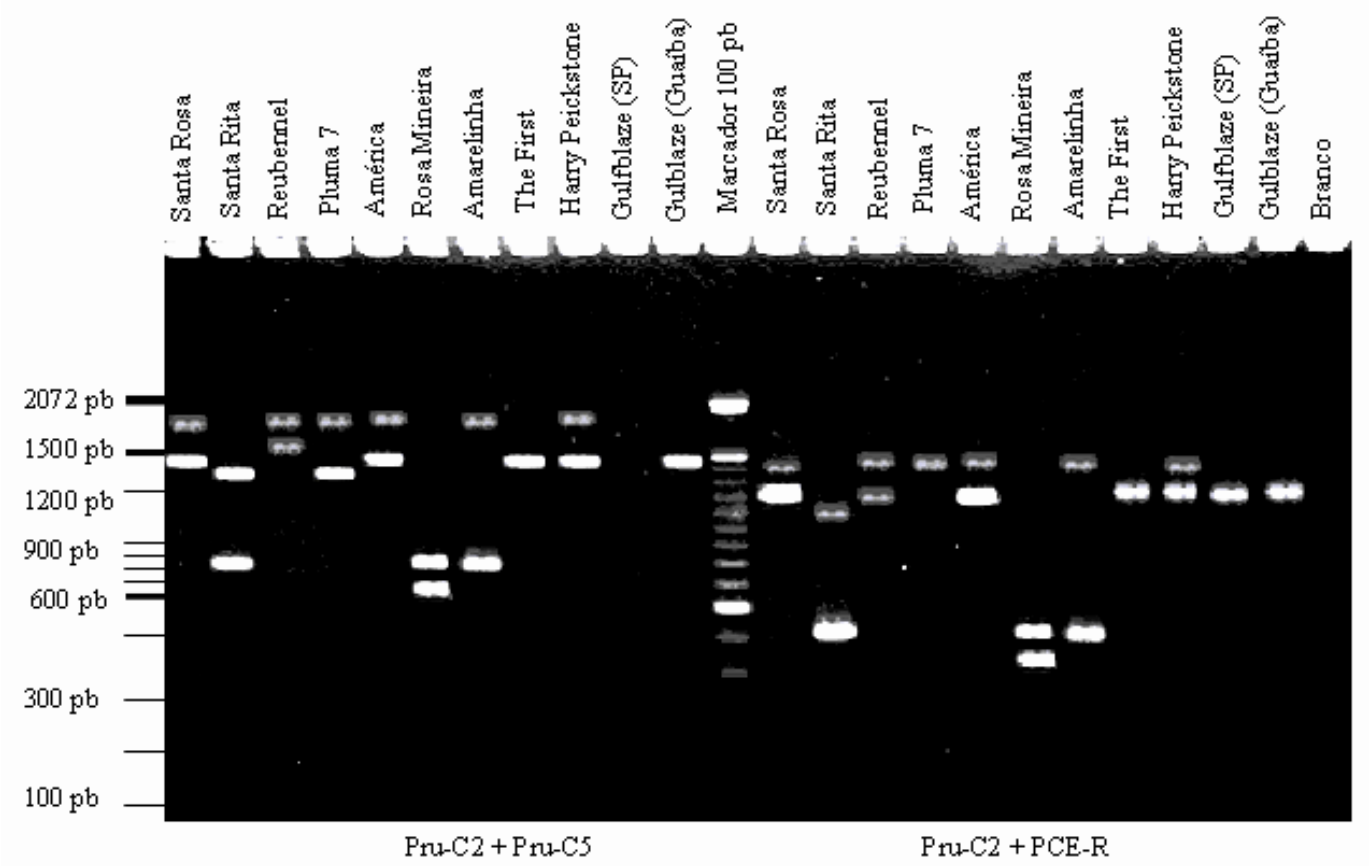

FIGURA 1 - Padrões de amplificação de alelos-S obtidos com os iniciadores Pru- $\mathrm{C}_{2} / \mathrm{Pru}_{5} \mathrm{C}_{5}$ e Pru-C $\mathrm{C}_{2} / \mathrm{PCE}-\mathrm{R}$ em 11 cultivares de ameixeira-japonesa.

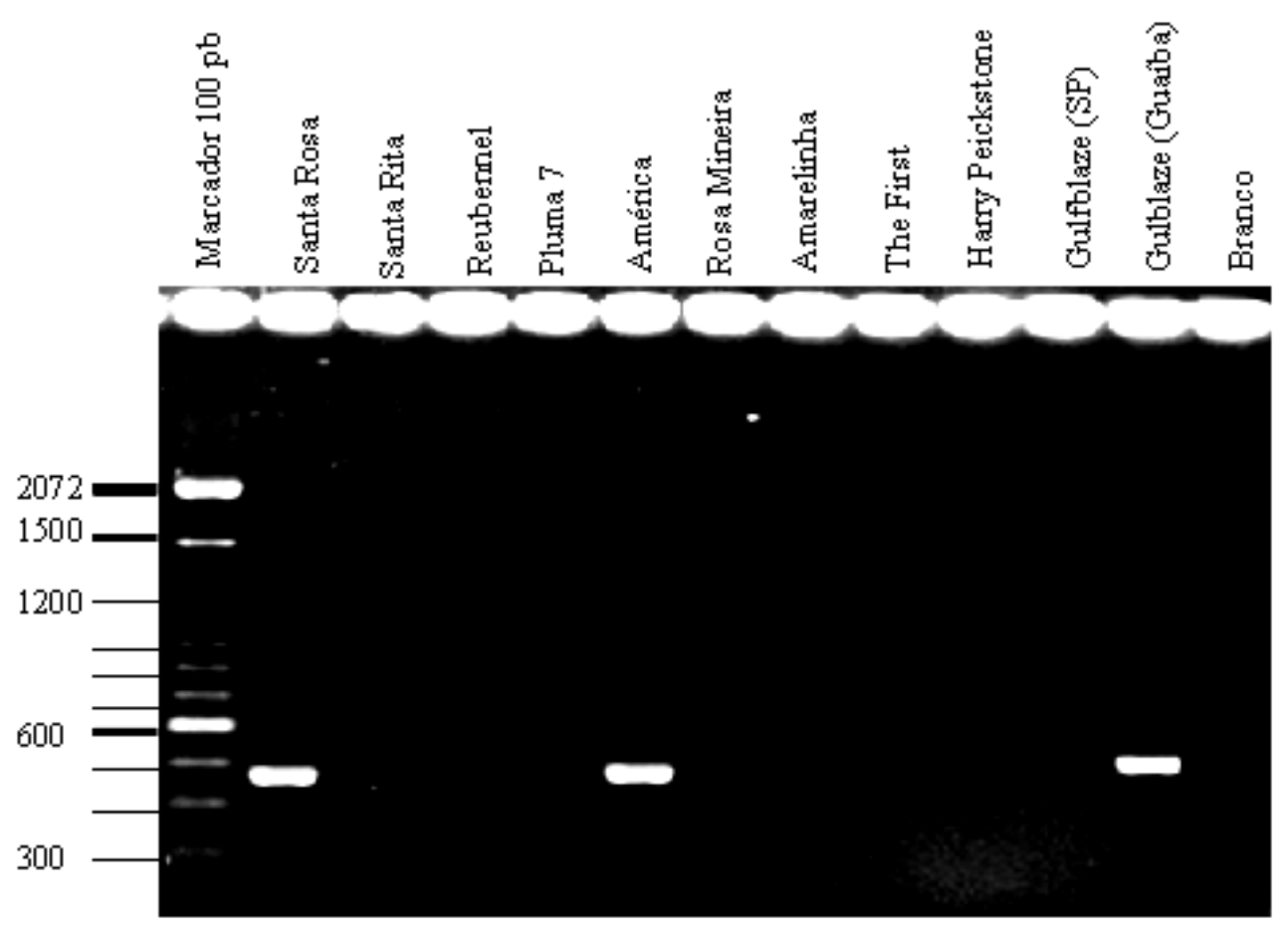

$\mathrm{I} Z 1+\mathrm{IZ} 4$

FIGURA 2 - Padrões de amplificação de alelos-S em 11 cultivares de ameixeira-japonesa com os iniciadores $\mathrm{IZ}_{1} / \mathrm{IZ}_{4}$. 


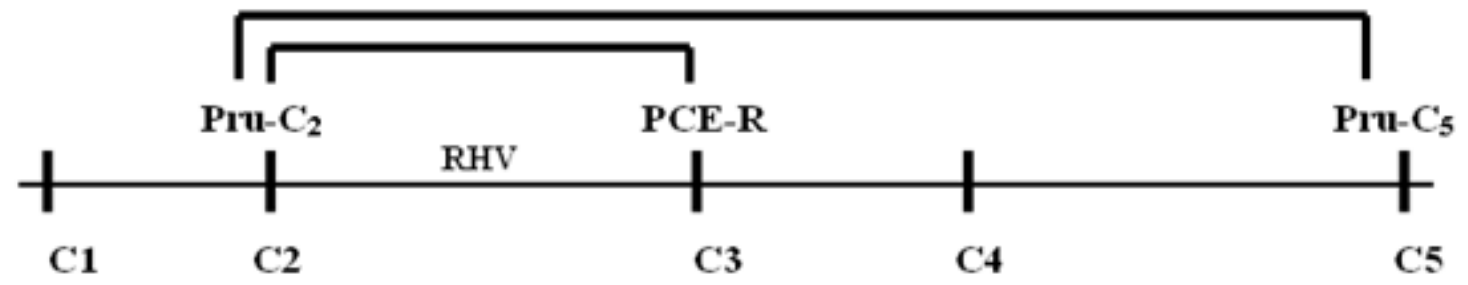

FIGURA 3 - Representação esquemática das regiões conservadas para alelos-S em Rosáceas, C1, C2, C3, C4 e C5 adaptado de Beppu (2002). Localização das sequências dos iniciadores utilizados em análise de PCR, Pru- $\mathrm{C}_{2}$, PCE-R, Pru- $\mathrm{C}_{5}$ e da região hipervariável (RHV).

TABELA 1 - Combinação de iniciadores usados na amplificação de alelos-S, com suas respectivas sequências de nucleotídeos e temperatura de anelamento. UFPel/Pelotas, 2008

\begin{tabular}{clcc}
\hline $\begin{array}{c}\text { Designação } \\
\text { do iniciador }\end{array}$ & \multicolumn{1}{c}{ Sequência $\left(5^{\prime}-3^{\prime}\right)$} & $\begin{array}{c}\text { Temperatura } \\
\text { anelamento }\left({ }^{\circ} \mathrm{C}\right)\end{array}$ & Referência \\
\hline $\begin{array}{c}\text { Pru-C } \\
\text { PCE-R }\end{array}$ & $\begin{array}{l}\text { CTA TGG CCA AGT AAT TAT TCA AAC C } \\
\text { TGT TTG TTC CAT TCG CYT TCC C }\end{array}$ & 54 & $\begin{array}{c}\text { Tao et al., 1999, } \\
\text { Yamane et al., } \\
\text { Pru-C }\end{array}$ \\
Pru-C $_{5}$ & CTA TGG CCA AGT AAT TAT TCA AAC C & 54 & Tao et al., 1999 \\
$\mathrm{IZ}_{1}$ & TAC CAC TTC ATG TAA CAA CTG AG & & \\
$\mathrm{IZ}_{4}$ & CCC ACC TAT TCT ACC GTT TG & 56 & Sapir, 2004 \\
\hline
\end{tabular}

TABELA 2 - Combinação de iniciadores e tamanho aproximado (em pares de bases) dos alelos-S amplificados em cultivares de ameixeira-japonesa

\begin{tabular}{lccc}
\hline \multicolumn{1}{c}{ Cultivar } & $\begin{array}{c}\text { Iniciadores } \\
\text { Pru-C }\end{array}$ + Pru-C & $\begin{array}{c}\text { Iniciadores } \\
\text { Pru-C }\end{array}$ & $\begin{array}{c}\text { Iniciadores } \\
\mathbf{I Z}_{\mathbf{1}}+\mathbf{I Z}_{\mathbf{4}}\end{array}$ \\
\cline { 2 - 4 } Santa Rosa & $1.900-1.450$ & $1.400-1.200$ & 460 \\
Santa Rita & $1.400-800$ & $1.100-500$ & - \\
Reubennel & $1.900-1.600$ & $1.400-1.300$ & - \\
Pluma 7 & $1.900-1.400$ & 1.400 & - \\
América & $1.900-1.450$ & $1.400-1.200$ & 460 \\
Rosa Mineira & $800-600$ & $500-400$ & - \\
Amarelinha & $1.900-800$ & $1.400-500$ & - \\
The First & 1.450 & 1.200 & - \\
Harry Pickstone & $1.900-1.450$ & $1.400-1.200$ & - \\
Gulfblaze (CSP) & - & 1.200 & - \\
Gulfblaze (CG) & 1.450 & 1.200 & 460 \\
\hline
\end{tabular}


TABELA 3 - Cultivares de ameixeira-japonesa e seus respectivos polinizadores definidos por meio de testes de polinização a campo, conforme Castro (2003), e a partir da análise molecular de alelos-S.

\section{Cultivares}

Produtoras Tradicionais*

\section{Cultivares Polinizadoras} (Indicadas a partir de dados moleculares)

Santa Rosa Santa Rita, The First e Wickson

Santa Rita Santa Rosa, Methley e The First

Santa Rita, Rosa Mineira

Santa Rosa, Reubennel, América, The First, Harry Pickstone, Gulfblaze (CG)

Reubennel Rosa Mineira, Amarelinha e Pluma 7 Rosa Mineira, The First, Gulfblaze (CG)

Pluma $7 \quad$ Blood Plum, Amarelinha

Rosa Mineira, The First, Gulfblaze (CG)

América Reubennel, Rosa Mineira

Rosa Mineira, Santa Rita

Rosa Mineira Relativa autofertilidade

Amarelinha Blood Plum, Pluma 7 e Friar

The First Santa Rita, Santa Rosa e Methley

Harry Pickstone Wade, Wickson

Santa Rosa, Reubennel, Pluma 7, América, The First, Harry Pickstone, Gulfblaze (CG)

The First, Gulfblaze (CG)

Santa Rita, Reubennel, Pluma 7, Rosa Mineira, Amarelinha

Santa Rita, Rosa Mineira

Gulfblaze (CSP)Seleções Fla 87-1 e Fla 87-2

Reubennel, Pluma 7, Rosa Mineira, Amarelinha

Gulfblaze (CG) Não relatado

Reubennel, Pluma 7, Rosa Mineira, Amarelinha

TABELA 4 - Cultivares e iniciadores usados na amplificação e tamanho dos alelos-S purificados e submetidos ao sequenciamento

\begin{tabular}{|c|c|c|c|c|c|c|c|}
\hline Cultivares & Iniciadores & $\begin{array}{l}\text { Tam. alelo } \\
\text { Amplificado } \\
\text { (pb) }\end{array}$ & $\begin{array}{l}\text { Iniciado- } \\
\text { res* }\end{array}$ & $\begin{array}{c}\text { Tam. } \\
\text { alelo } \\
\text { sequenciado } \\
(\mathrm{pb})\end{array}$ & $\begin{array}{l}\text { Acesso no } \\
\text { BLAST }\end{array}$ & $\begin{array}{l}\text { Identidade } \\
\text { com alelos }\end{array}$ & $\begin{array}{l}\text { Citação no } \\
\text { BLAST }\end{array}$ \\
\hline América & $\mathrm{IZ}_{1}+\mathrm{IZ}_{4}$ & 460 & $\mathrm{IZ}_{1}$ & 448 & $\begin{array}{l}\text { DQ646489.1 } \\
\underline{\text { AF432418.1 }}\end{array}$ & $\begin{array}{l}100 \% \mathrm{~S}^{\mathrm{c}} \\
99 \% \mathrm{~S}^{4}\end{array}$ & $\begin{array}{l}\text { Sapir e Goldway, } 2006 \\
\text { Sapir e Goldway, } 2001\end{array}$ \\
\hline Santa Rosa & $\mathrm{IZ}_{1}+\mathrm{IZ}_{4}$ & 460 & $\mathrm{IZ}_{1}$ & 414 & $\begin{array}{l}\text { DQ646489.1 } \\
\text { AF432418.1 }\end{array}$ & $\begin{array}{l}100 \% \mathrm{~S}^{\mathrm{c}} \\
99 \% \mathrm{~S}^{4}\end{array}$ & $\begin{array}{l}\text { Sapir e Goldway, } 2006 \\
\text { Sapir e Goldway, } 2001\end{array}$ \\
\hline Rosa Mineira & Pru- $\mathrm{C}_{2}+$ Pru- $\mathrm{C}_{5}$ & 600 & Pru- $\mathrm{C}_{2}$ & 306 & $\underline{\mathrm{AB} 084149.1}$ & $87 \% \mathrm{~S}^{\mathrm{i}}$ & Beppu et al., 2002 \\
\hline Rosa Mineira & Pru- $\mathrm{C}_{2}+$ Pru- $\mathrm{C}_{5}$ & 800 & Pru- $\mathrm{C}_{5}$ & 200 & $\underline{\mathrm{AB} 084149.1}$ & $\begin{array}{l}94 \% \mathrm{~S}^{\mathrm{i}} \\
88 \% \mathrm{Sa}^{\mathrm{a}}\end{array}$ & Beppu et al., 2002 \\
\hline Rosa Mineira & Pru-C ${ }_{2}+$ PCE-R & 500 & PCE-R & 110 & $\begin{array}{l}\text { DQ512914.1 } \\
\underline{A B 084148.1}\end{array}$ & $\begin{array}{l}90 \% \mathrm{~S}^{\mathrm{h}} \\
90 \% \mathrm{~S}^{\mathrm{h}}\end{array}$ & $\begin{array}{l}\text { Zhang et al., } 2006 \\
\text { Beppu et al., } 2002\end{array}$ \\
\hline Rosa Mineira & Pru- $\mathrm{C}_{2}+$ PCE-R & 400 & PCE-R & 110 & AB252411.1 & $82 \% \mathrm{~S}^{\mathrm{a}}$ & Tao et al., 2006 \\
\hline Santa Rita & Pru- $\mathrm{C}_{2}+$ Pru- $\mathrm{C}_{5}$ & 500 & Pru- $\mathrm{C}_{5}$ & 96 & $\underline{\mathrm{AB} 084149.1}$ & $94 \% \mathrm{~S}^{\mathrm{h}}$ & Beppu et al., 2002 \\
\hline América & Pru- $\mathrm{C}_{2}+$ Pru- $\mathrm{C}_{5}$ & 1400 & Pru- $\mathrm{C}_{5}$ & 30 & $* *$ & & \\
\hline
\end{tabular}

*Iniciadores usados no sequenciamento; * *baixa identidade com alelos- $S$. 


\section{CONCLUSÕES}

1-As condições de PCR e as combinações de iniciadores utilizados permitem a caracterização de alelos-S nas cultivares de Prunus salicina estudadas, possibilitando a seleção de cultivares compatíveis reprodutivamente.

2-A obtenção de sequências mais completas de um maior número de alelos-S se faz necessário para o estabelecimento de uma relação de identidade precisa entre os mesmos.

\section{AGRADECIMENTOS}

Agradecemos o apoio financeiro fornecido pela CAPES, através da concessão da bolsa de estudos e compra de equipamentos via edital Pró-Equipamentos $n^{\circ} 1918 / 2007$, e CNPq por meio do projeto Edital MCT/CNPq 15/2007 - Universal -Faixa A.

\section{REFERÊNCIAS}

BARBOSA, W. Gulfblaze: nova opção de ameixa para o estado de Aão Paulo. 2006. Disponível em: $<$ http://www.infobibos.com/Artigos/Ameixa/Ameixa.htm>. Acesso em: 20 maio 2008.

BEPPU, K.; YAMANE, H.; YAEGAKI, H.; YAMAGUCHI, M.; KATAOKA, I.; TAO, R. Diversity of S-RNase genes and S-haplotypes in Japanese plum (Prunus salicina Lindl.). Journal of Horticultural Science \& Biotechnology, United Kingdom, v.77, n.6, p.658-664, 2002.

BLAST/NCBI - Disponível em: <http://blast.ncbi. nlm.nih.gov/Blast.cgi> . Acesso em: 20 mar. 2008.

BOSKOVIC, R.; TOBUTT, K.R. Correlation of stylar ribonuclease zymograms with incompatibility alleles in sweet cherry. Euphytica, Netherlands, v.90, p.245-250, 1996.

BROOTHAERTS, W.; JANSSENS, G.A.; PROOST, P.; BROEKAERT, W.F. cDNA cloning and molecular analysis of two self-incompatibility alleles from apple. Plant Molecular Biology, Netherlands, v.27, p.499-511, 1995.
BRUCKNER, C.H. Autoincompatibilidade no maracujá (Passiflora edulis Sims). 1994. 85 f. Tese (Doutorado) - Universidade Federal de Viçosa, Viçosa, MG. 1994.

CALLEN, D.F.; THOMPSON, A.D.; SHEN, Y.; PHILLIPS, H.A.; RICHARDS, H.I.; MULLEY, J.C.; SUTHERLAND, G.R. Incidence and origin of "null alleles" in the "AC" microsatellite markers. American Journal of Human Genetics, Chicago, v.52, p.922-927, 1993.

CASTRO, L.A.S. Ameixa produção. Pelotas: Embrapa-SPI, 2003. 115p. (Frutas do Brasil, 43).

CHAGAS, E.A.; PIO, R.; BARBOSA, W.; DALL 'ORTO, F.A.C. Aspectos técnicos do cultivo da ameixeira. 2006. Disponível em: <http://www. infobibos.com/Artigos/2006_3/ameixeira/index. htm>. Acesso em: 08 fev. 2007.

DE NETTANCOUT, D. Incompatibility and incongruity in wild and cultivated plants. Berlin: Springer, 2000. 320p.

DE NETTANCOUT, D. Incompatibility in angiosperms. Berlin: Springer, 1997. 230p.

DOYLE, J.J.; DOYLE, J.L. Isolation of plant DNA from fresh tissue. Focus, Rochestes, v.1, p.13-15, 1991.

EMBRAPA - Empresa Brasileira de Pesquisa Agropecuária, Clima Temperado. Zoneamento Agroclimático para Ameixeira no Rio Grande do Sul. Pelotas, 2005. (Documento, 151). Disponível em: $<$ http://www.cpact.embrapa.br/publicacoes/download/documentos/documento 151.pdf $>$. Acesso em: 25 mar. 2007.

ISHIMIZU, T.; INOUE, K.; SHIMONAKA, M.; SAITO, T.; TERAI, O.; NORIOKA, S. PCR-based method for identifying the S- genotypes of Japanese pear cultivars. Theoretical and Applied Genetics, Heidelberg, v.98, p.961-967, 1999.

KAUFMANN, H.; KIRCH, H.; WEMMER, T. Sporophytic and gametophytic self-incompatibility. In: CRESTI, M.; TIEZZI, A. Sexual plant reproduction. Berlin: Springer, p.115-125, 1992. 
LEWIS, D. Gametophytic-sporophytic incompatibility. In: WILLIAMS, E.G.; CLARKE, A.E.; KNOX, R.B. Advances in cellular and molecular biology of plants: genetic control of self incompatibility and reproductive development in flowering plants. Dordrecht: Kluwer Academic Publishers, 1994. v.2, p.88-101.

MOTA, M.; OLIVEIRA, C. M. Identificação de alelos $S$ na pereira 'Rocha' e determinação da compatibilidade entre cultivares, 2005. Disponível em: <http://www.isa.utl.pt/files/pub/id/Mota_Oliveira_2005_ActaPortHort1.pdf> Acesso em: 14 maio 2007 .

NEWBIGIN, E.; ANDERSON, M.A.; CLARKE, A.E. Gametophytic self-incompatibility systems. The Plant Cell, Rockville USA, v.5, p.1315-1324, 1993.

RASEIRA, M.C.B. Polinização. In: CASTRO, L.A.S. Ameixa: produção. Pelotas: EMBRAPA Clima Temperado, 2003. p.30-33.

SAKURAI, K.; BROWN, S.K.; WEEDEN, N.F. Self- incompatibility alleles of apple cultivars and advanced selection. HortScience, Alexandria, v.35, p.116-119, 2000.

SAPIR G.; STERN, R.A.; EISIKOWITCH, D.; GOLDWAY, M. Cloning of four new Japanese plum S-alleles and determination of the compatibility between cultivars by PCR analysis. The Journal of Horticultural Science and Biotechnology, Warwick, v.79, n.2, p.223-227, 2004.

SCHIFINO-WITTMANN, M.T.; DALL'AGNOL, M. Self-incompatibility in plants. Ciência Rural, Santa Maria, v.32, n.6, p.1083-1090, 2002.

SEGANFREDO, R.; NACHTIGAL, J.C.; KERSTEN, E. Influência do ácido indolbutírico e de épocas de coleta de estacas no enraizamento de cultivares de ameixeira (Prunus salicina Lindl.). Revista Brasileira de Agrociência, Pelotas, v.1, n.1, p.40-42, 1995.
SILVEIRA, J.R.P.; SIMONETTO, P.R.; CASTRO, L.A.S. de; ROSSETO, E.A. Escaldadura das folhas da ameixeira. Porto Alegre: FEPAGRO, 2003. 33p. (Circular Técnica, 24).

TAO, R.; HABU, T.; NAMBA, A.; YAMANE, H. Inheritance of $\mathrm{S}^{\mathrm{f}}$-RNase in Japanese apricot (Prunus mume) and its relation to self-compatibility. Theoretical and applied Genetics, Heidelberg, v.105, p.222-228, 2002a.

TAO, R.; HABU, T.; YAMANE, H.; SUGIURA, A. Characterization and cDNA cloning for $\mathrm{S}^{\mathrm{f}}$-RNase, a molecular marker for self-incompatibility, in Japanese apricot (Prunus mume). Journal of the Japanese Society for Horticultural Science, Tokyo, v.71, p.595-600, 2002b.

TAO, R.; YAMANE, H.; SUGIURA, A. Molecular Typing of S-alleles through identification, characterization and cDNA cloning for S-RNases in Sweet Cherry. Journal of the American Society for Horticulture Science, Mount Vermon, v.124, n.3, p.224-233, 1999.

THOMPSON, J.D.; GIBSON, T.J.; PLEWNIAK, F.; JEANMOUGIN, F.; HIGGINS, D.G. The CLUSTALX windows interface: flexible strategies for multiple sequence alignment aided by quality analysis tools. Nucleic Acids Research, Oxford, v.24, p.4876-4882, 1997.

YAEGAKI, H.; SHIMADA, T.; MORIGUCHI, T.; HAYAMA, H.; HAJI, T.; YAMAGUCHI, M. Molecular characterization of S-RNase genes and S-genotypes in the Japanese apricot (Prunus mume Sieb. et Zucc.). Sexual Plant Reproduction, Berlin, v.13, p.251-257, 2001.

YAMANE, H.; TAO, R.; SUGIURA, A.; HAUCK, N.R.; IEZZONI, A.F. Identification and characterization of $S$-RNases in tetraploid sour cherry (Prunus cerasus L.). Journal of the American Society for Horticulture Science, Mount Vermon, v.126, p.661-667, 2001. 